\title{
Stage IIIB Cervical Cancer FIGO 2018
}

National Cancer Institute

\section{Source}

National Cancer Institute. Stage IIIB Cervical Cancer FIGO 2018. NCI Thesaurus. Code C162241.

Cervical carcinoma with extension to the pelvic wall and/or hydronephrosis or nonfunctioning kidney (unless known to be due to another cause). (FIGO 2018) 